\title{
RETRACTION: Study on Supply Chain Financial Modeling of Multilayer Networks Yuanshuang Zhao
}

Department of Business School, University of Jinan, Jinan 250022. zhaoyuanshuang2011@163.com

Keywords: Multilayer Network; Supply Chain; Financial Modeling Issue

\begin{abstract}
Under new economical situation, business operation and investment are facing new opportunities and challenges. With the expansion of supply chain financial market, supply chain finance needs remodeling and transformation, forming multilayer network structere. In this regard, this paper discusses the construction method of the multilayer network system in su nly chain from the whole process of logistics management, the overall network layout and th trat sformation and upgrading of the supply chain finance. Then it analyzes the problem o sup s y chain financial modeling and then improves the multilayer supply chain network to st eng ten the prevention of financial risks.
\end{abstract}

\section{Introduction}

In face of the complex and changeable market situation $/ \mathrm{dd} / \mathrm{m}$ reasingly fierce competition in the industry, in order to gain an advantage and occupy a larger ma ket share, enterprises should improve and innovate its management strategy, build a scientific and perfect supply chain system, and form a multilayer network. In the process, combined with fmancial theory, through financial market modeling, it can accurately simulate the market harac teristics, and then reflect the dynamic changes of the market, make it easy to make predicions, and provide an important reference for business strategy and investment decision making

\section{Construction of multilayer net work system in supply chain}

\subsection{Whole course logistics maproment service}

To establish a scientitil and practical supply chain multilayer network, it is necessary to investigate the envirorme. Or the supply chain, pay close attention to its fluctuation and reduce its instability and unce ta nty. strengthen the cooperation and exchange among all nodes, share some data and information, highlight the tender management of supply chain management and provide distinctive full-sc vice logistics management service for upstream and downstream enterprises. In view of su, ri ars. tactories, warehouses, markets and other logistics nodes, the number of suitable facilities, the 5 graphical location and size of each facility, procurement requirements, supply plans and distribution plans need to be clearly defined and the production and supply costs, inventory holding costs, order processing costs and shipping costs need to be strictly controlled. In the multilayer network of supply chain, it realizes information, intelligent physical work, product production, supply, and storage information can be traced all the way, it also shows good ability and level in the aspects of order processing, multi owner management and information management in each node enterprise.

The production capacities of plant $\mathrm{P} 1$ and plant $\mathrm{P} 2$ are 100,000 and 30,000 respectively, the consumption demand of $\mathrm{C} 1, \mathrm{C} 2$ and $\mathrm{C} 3$ in consumer market are 25,000, 50,000 and 25,000 respectively, the logistics cost table, production and supply allocation volume and the improved logistics cost table are shown in Table 1, 2, 3 and 4, and the logistics node and unit cost are shown in Figure 1.

This article (https://doi.org/10.2991/ssehr-17.2018.135) has been retracted at the request of the conference committee board. All authors agree with the retraction. 
Table 1 Logistics cost table

\begin{tabular}{cccccc}
\hline & P1 & P2 & C1 & C2 & C3 \\
\hline W1 & 2 & 1 & 2 & 5 & 4 \\
W2 & 2 & 5 & 1 & 2 & 1 \\
\hline
\end{tabular}

Table 2 Production and supply distribution

\begin{tabular}{cccccc}
\hline & $\mathrm{P} 1$ & $\mathrm{P} 2$ & $\mathrm{C} 1$ & $\mathrm{C} 2$ & $\mathrm{C} 3$ \\
\hline $\mathrm{W} 1$ & 0 & 0 & 0 & 0 & 0 \\
$\mathrm{~W} 2$ & 100,000 & 30,000 & 25,000 & 50,000 & 25,000 \\
\hline
\end{tabular}

Table 3 Improved logistics cost table

\begin{tabular}{cccccc}
\hline & $\mathrm{P} 1$ & $\mathrm{P} 2$ & $\mathrm{C} 1$ & $\mathrm{C} 2$ \\
$\mathrm{~W} 1$ & 0 & 0 & 0 & 0 \\
$\mathrm{~W} 2$ & 200000 & 150000 & 25000 & 100006 & $\mathrm{C} 3$ \\
\hline
\end{tabular}

Table 4 Improved distribution of production sup $1 \mathrm{y}$

\begin{tabular}{cccccc}
\hline & $\mathrm{P} 1$ & $\mathrm{P} 2$ & $\mathrm{C} 1$ & $\mathrm{C} 3$ \\
\hline $\mathrm{W} 1$ & 30000 & 0 & 25000 & $y$ & 0 \\
$\mathrm{~W} 2$ & 70000 & 30000 & 0 & 30000 & 25000 \\
\hline
\end{tabular}

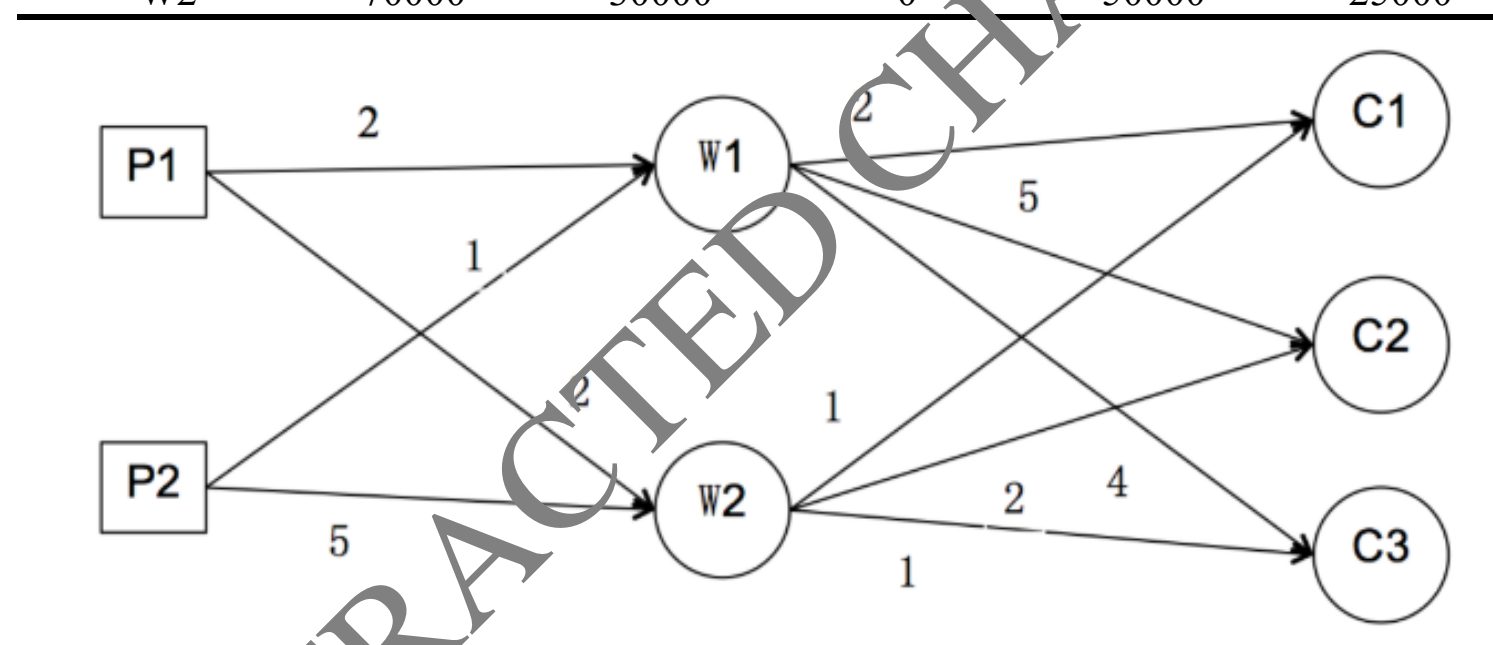

Figure 1 Logistics node and unit cost

\subsection{Optimization and Integration of overall Network layout}

With the ${ }^{1}$ loxpansion of enterprise business, it is necessary to actively face the complex and changeable mo,ket situation and increasingly fierce industry competition. In order to win the advantage, the enterprise needs to improve its management and development strategy and upgrade and innovate the supply chain. On the basis of the original supply chain nodes, it is deployed in the blank area of the market to provide support for the construction of the supply chain of the multilayer network so as to realize the optimization and integration of the overall network layout. In this process, on the basis of the innovative business mode, we must improve its service capabilities, provide better quality services, and apply information technology and automation technology to improve service capabilities. The electronic label picking system, barcode recognition system and warehouse information management system have become part of the multi-layer network structure of the supply chain. Two-layer and two-and-a-half network structures are shown in Figure 2 and Figure 3: 


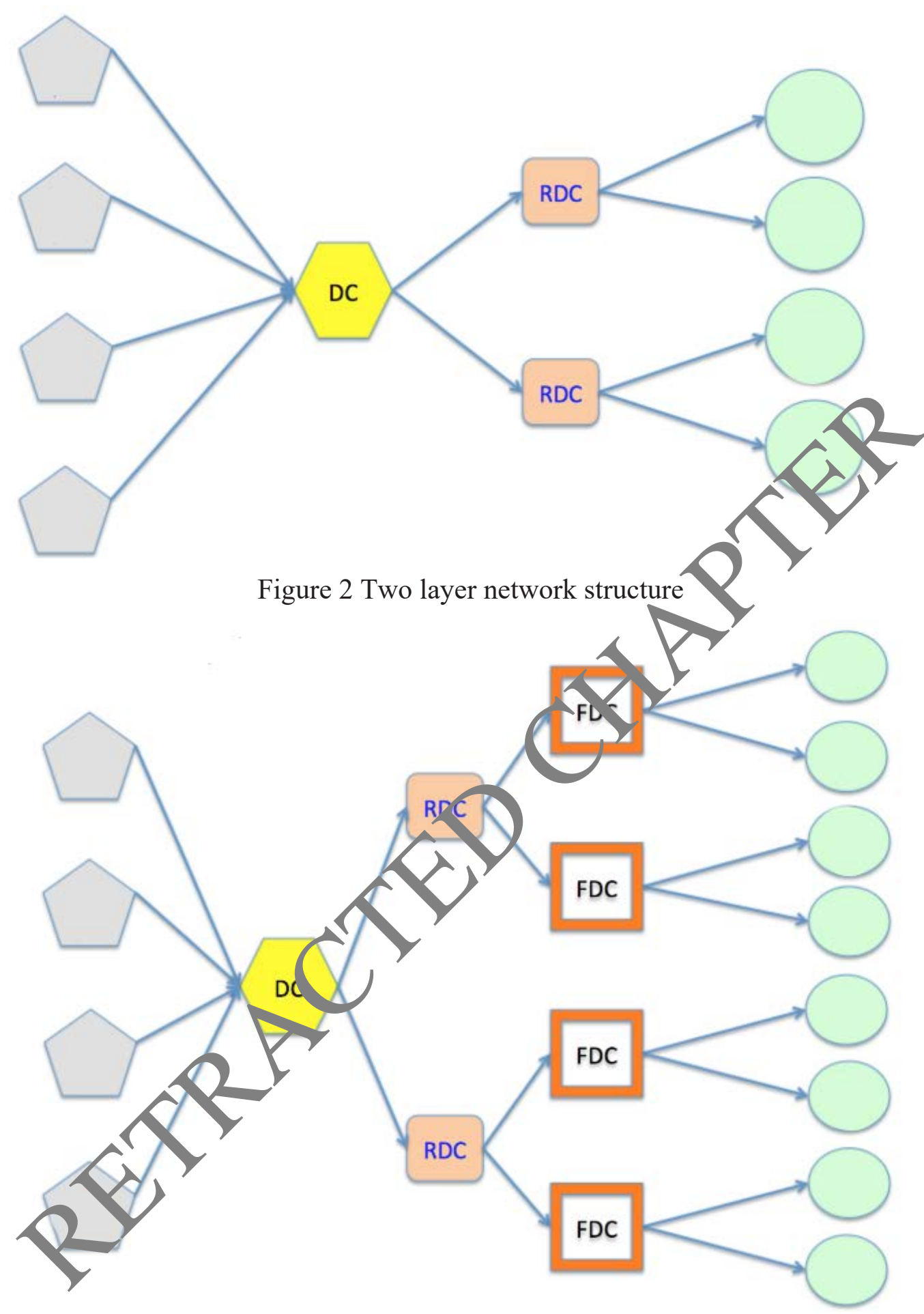

Figure 3 Two-and-a-half network

\subsection{The transformation and upgrading of Supply Chain Finance}

With the advent of the era of industrial Internet of things, digitalization, intelligence and networking have become the main trend of development. Under the new economic situation, the construction of a multilayer supply chain network requires organic integration of manufacturing, finance and technology. With the encouragement of policies, technological upgrading and industrial transformation, the supply chain financial market is gradually expanding. The supply chain finance of multilayer network needs to pay close attention to the market reaction and adjust the production capacity accordingly. The business model of supply chain finance has shifted from the traditional centralized mode to the smart mode. The technologies such as Internet of Things, artificial 
intelligence and big data play an important role in it, and the service capability and efficiency have been greatly improved. "E-Commerce Platform + Supply Chain Finance", "Industrial Group + Supply Chain Finance" and other models have become the main trend, providing a new way of thinking for the business development of the new era.

\section{Modeling of supply chain finance based on multilayer network}

The transformation and upgrading of supply chain finance have created good opportunities for the development of enterprises and even the whole industry, but at the same time, it also faces certain risks and challenges. It is necessary to have a comprehensive and specific understanding of the financial markets and to master their dynamic changes and to judge their impact on supply chain finance and make corresponding adjustments and changes so as to provide reference for business operations and investment decisions.

\subsection{Multi-agent financial market model}

The multi-agent financial market model is of hierarchical and dynami flex. 10 and changeable, and can be better adapted to the dynamic changes in the financial market In th supply chain finance of multilayer networks, the main body is clearly defined and the cha racteristics of the autonomy, communicability, reaction ability and spontaneous behavior are b ced or the autonomy of the main body. By the role of the external environment, the intelligent stbjet to respond accordingly, around the common goals and tasks, interaction and collaboration. T/ re is a loose or close relationship between the subjects, which affects and restricts each otiner. + is necessary to grasp every step and step by multi-agent financial modeling with the practic 1 and operability ABM method. First of all, a clear goal should be defined, reference needs to be made on realistic economic issues, the characteristics of multiple subjects and their i terac ions should be analyzed, and their behavior determined according to the state of the subject. n the same way, the behavior of the subject also affects the state of the subject. On this basis, he framework of the multi-agent financial market model is constructed. Then, combined with a ope ation of the economy, the main body behavior is programmed, the number of subjects is dete mined, and the initial values of multiple subjects are set. In this process, the selection of co nputej programming language is very important, and it needs to conform to the actual situation Fintury, the results of the model operation are analyzed and the economic theory is referred to.

\subsection{Statistical physical 0 .}

The construction of the statistical physical model can fully and reasonably explain the market phenomenon of he suppy chain finance, and can understand the internal and external interference and the influencin factors from it. By applying the theory of social imitation, the interaction analysis of multi-pa tic es (ising model) is transformed into individual behavior analysis from macro and micro perspec ives, respectively. Based on the probability density function, the characteristics of random travel market, transition market, chaotic market and cooperative market are studied. The change of market investors' behavior and mood will largely affect the state of financial market, and other main bodies in the supply chain of multilayer structure will also encounter this problem. Based on the calculation and analysis of probability density function, we can understand the interaction between market sentiment and economic environment, determine the internal and external factors of financial market, and understand the causes of risk. It is easy to prevent fundamentally and make scientific and perfect management and investment decisions.

\section{Conclusion}

In summary, the supply chain finance of multilayer network is modeled, the financial market environment is analyzed, the internal and external factors are understood, and the prevention and control of the risk factors are strengthened. Based on the multilayer supply chain network system, the 
overall network layout to achieve the optimal integration, and promote supply chain finance transformation and upgrading. Using multi-agent financial market model and statistical physical model to analyze, provide some basis and reference for financial market prediction, so as to help enterprises to make scientific management and investment decisions, and have a positive impact on the healthy development of enterprises and the whole industry.

\section{References}

[1] Pinho T M, Coelho J P, Veiga G, et al. A Multilayer Model Predictive Control Methodology Applied to a Biomass Supply Chain Operational Level[J]. Complexity, 2017, 2017:1-10.

[2] Caschili S, Medda F R, Wilson A. An Interdependent Multi-Layer Model: Resilience of International Networks[J]. Networks \& Spatial Economics, 2015, 15(2):313-335.

[3] Shafizadeh-Moghadam H, Hagenauer J, Farajzadeh M, et al. Performance analy i vi adial basis function networks and multi-layer perceptron networks in modeling urban c1 angs: a case study[J]. International Journal of Geographical Information Science, 2015, 29(4):60 -623 